\title{
Drug Induced Hypersensitivity Syndrome Secondary to Phenobarbitone
}

\author{
Syed Zia Inamdar ${ }^{1, \star}$, Seema Jakanur ${ }^{1}$, Pradeepthi Katragadda ${ }^{1}$, Ajit Janagond ${ }^{2}$, Mallinath \\ Paramagond', Raghavendra Vinayakarao Kulkarni', Akram Naikwadi ${ }^{3}$, Ananth Koth ${ }^{3}$, Arvind Patil ${ }^{4}$
}

1'Department of Pharmacy Practice, BLDEA's SSM College of Pharmacy and Research Centre, Vijayapura, Karnataka, INDIA. ${ }^{2}$ Department of Dermatology, Shri BM Patil Medical College Hospital and Research Centre, Vijayapura, Karnataka, INDIA. ${ }^{3}$ Department of Pharmacology, Shri BM Patil Medical College Hospital and Research Centre, Vijayapura, Karnataka, INDIA. ${ }^{4}$ Department of Surgery, Shri BM Patil Medical College Hospital and Research Centre, Vijayapura, Karnataka, INDIA.

\begin{abstract}
Phenobarbitone- a barbiturate, non-selective central nervous system depressant drug, primarily used as a sedative hypnotic and anticonvulsant in sub hypnotic doses. It has long term anticonvulsant effect, used in the treatment of generalized tonic-clonic and cortical local seizures. It is also effective in acute convulsive episodes associated with status epileptic's cholera, eclampsia, meningitis, tetanus and toxic reactions to strychnine or local anesthetics. The present case report describes the occurrence of anticonvulsant drug induced hypersensitivity drug reaction followed after to the use of phenobarbitone in a pediatric patient prescribed to treat his seizure disorder. The suspected drug was immediately stopped and the patient was managed symptomatically. The causality assessment of the adverse effect revealed a "probable" causal relationship for the suspected drug and reaction was categorized as "moderately severe" in nature.
\end{abstract}

Key words: Anticonvulsant, Hypersensitivity, Adverse drug reaction, Phenobarbitone, Barbiturate, Pediatric.

\section{INTRODUCTION}

Phenobarbitone belongs to anticonvulsant drug class, it is a long acting barbiturate with a narrow therapeutic index and wide inter individual variability in the rate of metabolism. Barbiturate binds to the $\beta$ subunits of the $u$-aminobutyric acid a (gaba-a) receptors, increasing the duration of opening of the chloride ion channel and potentiating the neuroinhibitory effect of gaba. Anticonvulsant Hypersensitivity Syndrome (AHS) was a term first coined by shear and Spielberg [1, class ii] in 1988 to describe an idiopathic hypersensitivity reaction seen decades earlier in patients exposed to the traditional aromatic anticonvulsants. The traditional aromatic antiepileptic drugs (AEDS); phenytoin, carbamazepine, phenobarbital and primidone, have an aromatic benzene ring in common, the toxic arena oxide metabolite of which was first implicated as a potential trigger of AHS. ${ }^{1}$ aromatic anticonvulsant-induced Severe Cutaneous Adverse Drug Reactions (SCARS), such as
Stevens-Johnson Syndrome (SJS), Toxic Epidermal Necrosis (TEN) and Drug Rash with Eosinophilia and Systemic Symptoms (DRESS) or drug-induced hypersensitivity syndrome, are rare, but potentially fatal immune-mediated adverse drug reaction (ADR). SCARS typically appear 1-8 wk after receiving anticonvulsant drug. DRESS is characterized by fever, cutaneous rash, lymphadenopathy, eosinophilia and internal organ involvement. The incidence varies from 1:1000 to 1:10,000 exposures. SCARS are frequently associated with aromatic anticonvulsant drugs such as phenobarbital (pb), phenytoin (pht) and carbamazepine (cbz), which are the first-line drugs used in seizure disorder in children..$^{2-5}$

\section{CASE REPORT}

A 3 year old male pediatric patient was presented with symptoms of skin lesions over scalp, face, trunk, buttocks and both lower limbs since 25 days [Figure 1\& 2 ].
DOI: 10.5530/ijopp.13.3.48

Address for correspondence: Dr. Syed Zia Inamdar Professor and Clinical Pharmacist, Department of Pharmacy Practice, BLDEAs SSM College of Pharmacy and Research Centre, Vijayapura-586103, Karnataka, INDIA.

Phone no: +91- 9986666016 Email Id: syedzia.inamdar@ gmail.com

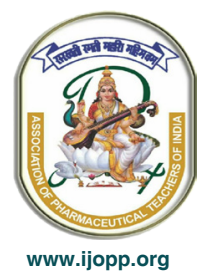



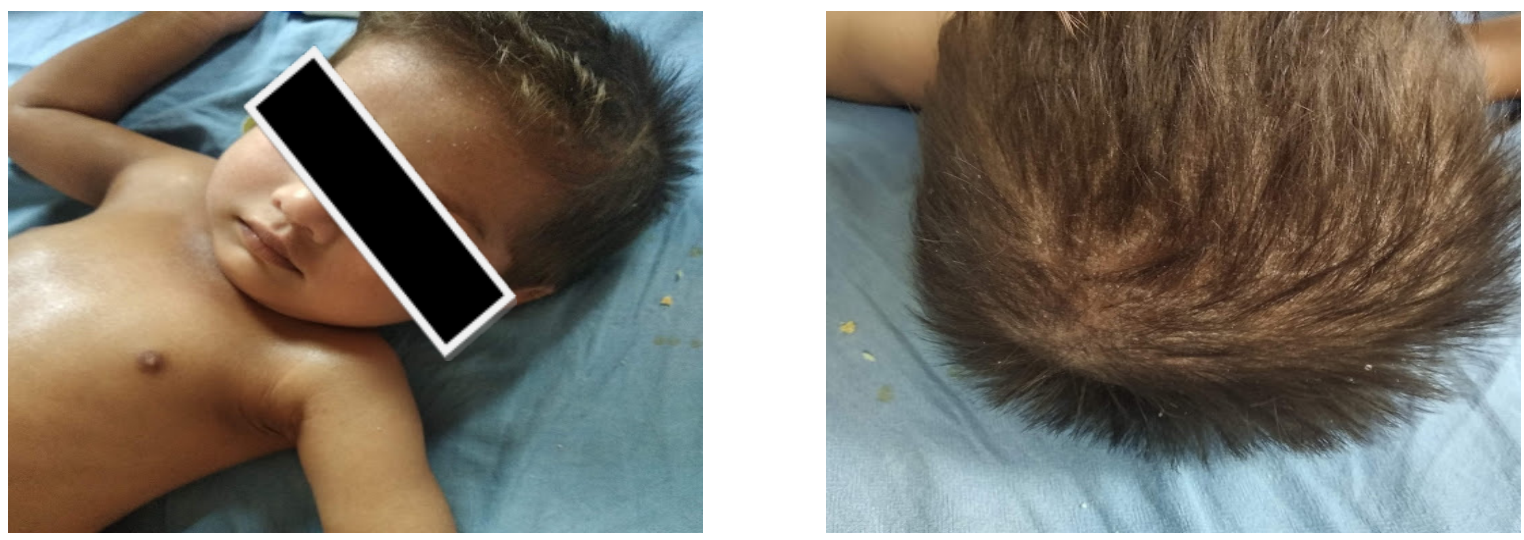

Figure 1 and 2: Phenobarbitone induced cutaneous lesions on trunk and scalp.

\begin{tabular}{|c|c|c|c|c|}
\hline Questions & Yes & No & Don't know/NA & Score* \\
\hline $\begin{array}{c}\text { Are there previous conclusive reports on this } \\
\text { reaction? }\end{array}$ & +1 & 0 & 0 & 1 \\
\hline $\begin{array}{c}\text { Did the adverse event appear after the suspected } \\
\text { drug was administered? }\end{array}$ & +2 & -1 & 0 & 2 \\
\hline $\begin{array}{l}\text { Did the adverse reaction improve when the drug } \\
\text { was discontinued or a specific antagonist was } \\
\text { administered? }\end{array}$ & +1 & 0 & 0 & 1 \\
\hline $\begin{array}{l}\text { did the adverse event reappear when the drug was } \\
\text { re-administered? }\end{array}$ & +2 & -1 & 0 & 0 \\
\hline $\begin{array}{l}\text { Are there alternative causes (other than the drug) that } \\
\text { could on their own have caused the reaction? }\end{array}$ & -1 & +2 & 0 & 2 \\
\hline Did the reaction reappear when a placebo was given? & -1 & +1 & 0 & 0 \\
\hline $\begin{array}{l}\text { Was the drug detected in blood (or other fluids) in } \\
\text { concentrations known to be toxic? }\end{array}$ & +1 & 0 & 0 & 0 \\
\hline $\begin{array}{l}\text { Was the reaction more severe when the dose } \\
\text { was increased or less severe when the dose was } \\
\text { decreased? }\end{array}$ & +1 & 0 & 0 & 0 \\
\hline $\begin{array}{c}\text { Did the patient have a similar reaction to the same or } \\
\text { similar drugs in any previous exposure? }\end{array}$ & +1 & 0 & 0 & 0 \\
\hline $\begin{array}{c}\text { Was the adverse event confirmed by any objective } \\
\text { evidence? }\end{array}$ & +1 & 0 & 0 & 1 \\
\hline Total & & & & 7 \\
\hline
\end{tabular}

[definite $\geq 9$ or greater, probable for a score of 5-8, possible for 1-4 and doubtful if the score is 0 ]. Report: the suspected adr found to be probable on naranjo causality assessment

Detailed past history revealed that the patient suffered with epilepsy for which he has been prescribed with phenobarbitone $30 \mathrm{mg}$ orally. Patient took the medication since $1 \frac{1}{2}$ month and it was after that he started developing red raised skin lesions which was sudden in onset and progressive in nature associated with itching for which oral cefixime was prescribed for 10 days and later was stopped by the pediatrician. There was history of low grade fever of since 20 days associated with cold and cough but not associated with chills and rigors. The skin lesions all over body were severe and the patient was immediately admitted to the teaching hospital and the suspected drug phenobarbitone was stopped. Peripheral smear report shows normocytic normochromic smear with lymphocytic leukocytosis and eosinophilia with reactive thrombocytosis. Multiple therapies were prescribed to the patient (tab deflazacort and levetiracetam, atarax, prednisolone sodium in the form of oral solution and white soft paraffin as topical moisturizer). The hematological investigation reported; wbc-21400, eosinophils- $16.3 \%$, platelet count-5.17, mch-24g/dl and mchc-30g/dl. The glucocorticoid doses were tapered appropriately with gradual resolution of the symptoms and the patient was discharged after complete ablation of lesions with proper instructions regarding the possible relapse.

Indian Journal of Pharmacy Practice, Vol 13, Issue 3, Jul-Sep, 2020 


\section{DISCUSSION}

Phenobarbitone was the first efficacious anti-epileptic introduced in 1912. It depresses the central nervous system by increasing the frequency and duration of chloride channels opening by acting on $\mathrm{GABA}^{\mathrm{A}}$ receptor subunits, thereby allowing a steady flow of these ions into neuronal cells which hyperpolarizes the cell's membrane and increases the threshold for the action potential, thus, effective in the treatment of seizures. ${ }^{5}$

Anticonvulsant Hypersensitivity Syndrome (AHS) as observed in the current case is a delayed adverse drug reaction likely to be associated with the use of aromatic anticonvulsant drug- phenobarbitone. AHS usually present with the classical symptoms that include dermatologic rashes, fever and evidence of systemic organ involvement. The diagnosis is often based on the recognition of these sign and symptoms and clinical judgment. The possible mechanism which thought to play have more or less these three components viz; deficiency or abnormality of the epoxide hydroxylase enzyme that detoxifies the metabolites of aromatic amine anticonvulsants, associated reactivation of herpes-type viruses and ethnic predisposition with certain human leukocyte antigen subtypes. The accumulation and binding of arena oxides, the toxic intermediate metabolite of anticonvulsant drugs to macromolecules, causes cell death and also act as prohaptens that bind to t cells, initiating an immune response and systemic reactions. The management includes withdrawal or discontinuation of associated anticonvulsant drug, use of systemic corticosteroids and related symptomatic treatment. The literature also reports cross sensitivity to other aromatic anticonvulsant drugs in $40-80 \%$ of ahs cases, warranting avoidance of aromatic anticonvulsant drug among patient with ahs history. Further, existence of familial association in patients with ahs history has exposed greater risk for the occurrence of ahs in patient's family members if they use aromatic anticonvulsant drugs. ${ }^{6}$

In the current case, the patient was presented with complaints of skin lesions over scalp, face, trunk, buttocks and both lower limbs. The initial assessment reveals use of Phenobarbitone $(30 \mathrm{mg}$ ) by the patient for the past 4 weeks to treat seizures. Suspecting phenobarbitone as a causative agent for the observed skin lesion the drug was immediately stopped and later substituted with levetiracetam to prevent the episodes of seizure. Tab deflazacort $12 \mathrm{mg}$ was prescribed for first 2 days followed by anti-histamine - atarax (bydroxyzine hydrochloride) and prednisolone for symptomatic management of the patient. Topical application of white soft paraffin and liquid paraffin were employed for moisturizing and soothing effect. A reduction in the skin lesions ensued after phenobarbitone withdrawal. The patient condition improved gradually and the lesions finally subsided at the time of discharge. Suspecting phenobarbitone as the probable cause for the observed adverse effect, a causality assessment was carried out using naranjo scale [Table 1] to assess the causal relationship. A total score of 7 was obtained, which indicates that there was a probability that the adverse reaction was caused due to the suspected drug itself. Hartwig's scale was used to assess the severity of the observed adverse effect which reported the severity as a moderately severe reaction. ${ }^{7}$

\section{CONCLUSION}

The suspected ADR was found to have "probable" causal relationship between the suspected drug phenobarbitone and the observed adverse drug reaction through Naranjo causality assessment. Severity assessment through hart wig's scale put the observed ADR under "moderately" severe reaction category. The report suggests close monitoring of phenobarbitone usage among patient population for the occurrence of anticonvulsant hypersensitivity reaction.

\section{ACKNOWLEDGEMENT}

The authors are thankful to the management of BLDE Association and BLDE Hospital and staff for supporting the work.

\section{CONFLICT OF INTEREST}

The author declares no conflict of interest exists.

\section{ABBREVIATIONS}

CNS: Central nervous system; GABA-A: Gamaaminobutyric acid-a;AHS: Anticonvulsant hypersensitivity syndrome; AEDS: Antiepileptic drugs; SCARs: Aromatic anticonvulsant-induced severe cutaneous adverse drug reactions; SJS: Stevens-johnson syndrome; TEN: Toxic epidermal necrosis; DRESS: Drug rash with eosinophilia and systemic symptoms; ADr: Adverse drug reaction; PB: Phenobarbital; PHT: Phenytoin; CBZ: Carbamazepine; MCHC: Mean corpuscular hemoglobin concentration; MCH: Mean corpuscular hemoglobin.

\section{SUMMARY}

A pediatric patient on phenobarbitone therapy to manage his seizures was presented to the hospital with the skin lesions all over the body which was later attributed to and caused by phenobarbitone as an anticonvulsant hypersensitivity drug reaction. 


\section{REFERENCES}

1. Ting ty. Anticonvulsant hypersensitivity syndrome: identification and management. Curr Treat Options Neurol. 2007;9(4):243-8. Doi:10.1007/ s11940-007-0010-9

2. Richard ah, david jq, herfinadal e, dick rg. Textbook of therapeutics, drug and disease management. 2006 ( $8^{\text {th }}$ ed.). Lippincott williams and wilkins.

3. Brizendine ce, naik pj. Drug rash with eosinophilia and systemic symptoms syndrome associated with use of phenytoin, divalproex sodium and phenobarbital. Am J Health Syst Pharm. 2013;70(6):507-10. Doi:10.2146/ ajhp120408

4. Manuyakorn $w$, siripool k, kamchaisatian $w$, pakakasama s, visudtibhan a, vilaiyuk s, rujirawat t, benjaponpitak s. Phenobarbital-induced severe cutaneous adverse drug reactions are associated with cyp2c19*2 in thai children. Pediatr Allergy Immunol. 2013;24(3):299-303. Doi: 10.1111/pai.12058.

5. Natt $\mathrm{nk}$, singh $\mathrm{t}$, singh $\mathrm{h}$, sharma $\mathrm{m}$, singh $\mathrm{g}$. Phenobarbitone induced drug reaction with eosinophilia and systemic symptoms (dress): a case report. Int $\mathrm{J}$ Basic Clin Pharmcol. 2013;2(3):333-5

6. Bohan $\mathrm{kh}$, mansuri tf, wilson $\mathrm{nm}$. Anticonvulsant hypersensitivity syndrome: implications for pharmaceutical care. Pharmacotherapy. 2007;27(10):1425-39. Doi: 10.1592/phco.27.10.1425.

7. Inamdar sz, joseph rp, k pradeepti, n ashwini, kulkarni rv. Etoricoxib induced skin rashes. Indian Journal of Pharmacy Practice. 2017;10(3):227-9. Doi: 10.5530/ijopp.10.3.46. 